\title{
Morphometric Analysis of Telencephalic Structure in a Variety of Neognath and Paleognath Bird Species Reveals Regional Differences Associated with Specific Behavioral Traits
}

\author{
Jeremy R. Corfield ${ }^{a} b$ J. Martin Wild ${ }^{a}$ Stuart Parsons ${ }^{b}$ M. Fabiana Kubke ${ }^{a}$ \\ ${ }^{a}$ Department of Anatomy with Radiology, and b School of Biological Sciences, University of Auckland, \\ Auckland, New Zealand
}

\author{
Key Words \\ Comparative neuroanatomy · Kiwi · Mosaic evolution • \\ Telencephalic evolution
}

\begin{abstract}
Birds exhibit a huge array of behavior, ecology and physiology, and occupy nearly every environment on earth, ranging from the desert outback of Australia to the tropical rain forests of Panama. Some birds have adopted a fully nocturnal lifestyle, such as the barn owl and kiwi, while others, such as the albatross, spend nearly their entire life flying over the ocean. Each species has evolved unique adaptations over millions of years to function in their respective niche. In order to increase processing power or network efficiency, many of these adaptations require enlargements and/or specializations of the brain as a whole or of specific brain regions. In this study, we examine the relative size and morphology of 9 telencephalic regions in a number of Paleognath and $\mathrm{Ne}-$ ognath birds and relate the findings to differences in behavior and sensory ecology. We pay particular attention to those species that have undergone a relative enlargement of the telencephalon to determine whether this relative increase in telencephalic size is homogeneous across different brain regions or whether particular regions have become differen-
\end{abstract}

tially enlarged. The analysis indicates that changes in the relative size of telencephalic regions are not homogeneous, with every species showing hypertrophy or hypotrophy of at least one of them. The three-dimensional structure of these regions in different species was also variable, in particular that of the mesopallium in kiwi. The findings from this study provide further evidence that the changes in relative brain size in birds reflect a process of mosaic evolution.

Copyright $\odot 2012$ S. Karger AG, Base

\section{Introduction}

Distinct sets of nuclei in the vertebrate brain are generally associated with different primary functions, so it is likely that behavioral changes associated with specific motor or sensory demands may lead to concomitant changes in the size of specific brain regions and/or in the organization of these regions. It is generally accepted that having a larger brain or brain region increases its information-processing power, thereby providing better integration and storage of information about the social and physical environment or the ability to modify or invent new behaviors [Jerison, 1973; Cluttonbrock and Harvey, 1980; Harvey et al., 1980; Lefebvre et al., 1997; Sol et al.,

\section{KARGER}

Fax +4161306 1234

E-Mail karger@karger.ch

www.karger.com
(C) 2012 S. Karger AG, Basel

0006-8977/12/0803-0181\$38.00/0

Accessible online at:

www.karger.com/bbe
Dr. Jeremy R. Corfield

Department of Neuroscience

University of Lethbridge

Lethbridge, AB T1K 3M4 (Canada)

Tel. +1 403332 5211, E-Mail jr.corfield@gmail.com 
2005]. Brains are thought to become enlarged through two different mechanisms: either the brain and major brain regions are enlarged as a whole (referred to as concerted evolution, passive or 'easy' mode) or specific regions are differentially enlarged (referred to as mosaic evolution, active or 'difficult' mode) [Jerison, 1985; Finlay and Darlington, 1995; Aboitiz, 1996; Finlay et al., 2001]. Variation in the size or makeup of individual brain regions indicates that mosaic evolution characterizes at least some of the diversification of avian and mammalian brain composition [Portmann, 1946; Cobb, 1964; Bang and Cobb, 1968; Bennett and Harvey, 1985; Healy and Guilford, 1990; Devoogd et al., 1993; Barton, 1996; Healy and Krebs, 1996; Glendenning and Masterton, 1998; Barton and Harvey, 2000; Timmermans et al., 2000; Clack et al., 2001; de Winter and Oxnard, 2001; Lefebvre et al., 2002; Whiting and Barton, 2003; Kubke et al., 2004; Iwaniuk and Wylie, 2006; Iwaniuk et al., 2008].

Neognathan birds, particularly parrots (Psittaciformes) and songbirds (Passeriformes) - especially corvids - have the largest relative telencephalon size [Portmann, 1946; Rehkämper et al., 1991; Iwaniuk and Hurd, 2005]. This enlargement has been suggested to be associated with a higher level of cognition (e.g. problem solving and memory) that allows these birds to perform complex tasks such as tool use, mirror self-recognition and planning for the future [Hunt, 1996; Clayton and Dickinson, 1998; Weir et al., 2002; Emery and Clayton, 2004; Emery, 2006; Prior et al., 2008; Raby et al., 2007]. The New Zealand kea (Nestor notabilis), for instance, is a species of parrot capable of great behavioral flexibility, sensorimotor intelligence and observational learning [Huber and Gajdon, 2006]. Similar cognitive abilities are also present in corvids, such as Western scrub jays (Aphelocoma californica), which demonstrate episodic-like memory and have the ability to remember specific past events [Clayton and Dickinson, 1998]. Also, New Caledonian crows are able to manufacture and use tools in the wild [Hunt, 1996].

In addition to an overall enlargement of the telencephalon, the enlargement of more specific brain regions and/ or the subdivisions of these regions are also correlated with specific behaviors in certain species [Cobb, 1964; Bang and Cobb, 1968; Bennett and Harvey, 1985; Healy and Guilford, 1990; Devoogd et al., 1993; Healy and Krebs, 1996; Timmermans et al., 2000; Lefebvre et al., 2002; Kubke et al., 2004; Iwaniuk and Wylie, 2006; Cnotka et al., 2008; Iwaniuk et al., 2008]. The ability for vocal learning, for instance, is well known to be restricted to only a few groups of birds (songbirds, hummingbirds and parrots), and in these species different nuclei make up the 'song system' distributed within several of the major telencephalic regions, with size differences that mirror the sexual dimorphism in song production [Nottebohm, 1981; Nottebohm et al., 1986; Devoogd et al., 1993; Smith et al., 1997].

Apart from oscines and parrots, the only other known taxon that has undergone a similar gross enlargement of the telencephalon is the New Zealand kiwi (Apteryx spp.) [Corfield et al., 2008]. Kiwi have adopted a nocturnal, ground-dwelling niche, in which they face a number of sensory challenges. Kiwi are unlikely to rely heavily on vision [Martin et al., 2007] and there is evidence that other sensory modalities, namely olfaction, somatosensation and audition, are well developed [Cobb, 1960; Bang and Cobb, 1968; Wenzel, 1968; 1971; Cunningham et al., 2007; Martin et al., 2007; Cunningham et al., 2009; Corfield et al., 2011].

We set out to examine the relative size of 9 telencephalic regions in a number of Neognath and Palaeognath birds to determine whether these regions scale homogeneously, especially in those species that show a telencephalic enlargement. Because morphological changes have also been observed in the telencephalon of birds [Stingelin and Senn, 1969], we also examined the overall morphology of the individual telencephalic regions using three-dimensional reconstructions. Our analysis indicates that different regions of the telencephalon are modified in size to different degrees, suggesting that avian telencephalic enlargements occur through mosaic evolution.

\section{Materials and Methods}

Three-dimensional modeling and volumetric estimation of telencephalic regions were undertaken on the brains of 13 bird species (table 1). Data from Corfield [2009] were augmented in the present study by the examination of additional specimens to increase sample sizes, thereby strengthening statistical power. Some discrepancies between the two studies probably resulted from these increases, and because the plots shown in the study by Corfield [2009: chapter 3] did not include any data on the olfactory bulb, entopallium or nucleus basorostralis. All material was obtained following University of Auckland and Department of Conservation regulations (research permits: NO-16732-FAU, NO18095-DOA and WA-24648-RES). All protected specimens were provided to us dead by conservation authorities or wildlife veterinarians. All other specimens were provided to us dead by local farmers or hunters, and thus no further ethics approvals were required.

All brains were submersion fixed in $4 \%$ paraformaldehyde in $0.01 \mathrm{M}$ phosphate-buffered saline (PBS), sectioned mid-sagittally 
Table 1. Volumes of the total brain, telencephalon, hindbrain and 9 telencephalic regions $\left(\mathrm{mm}^{3}\right)$

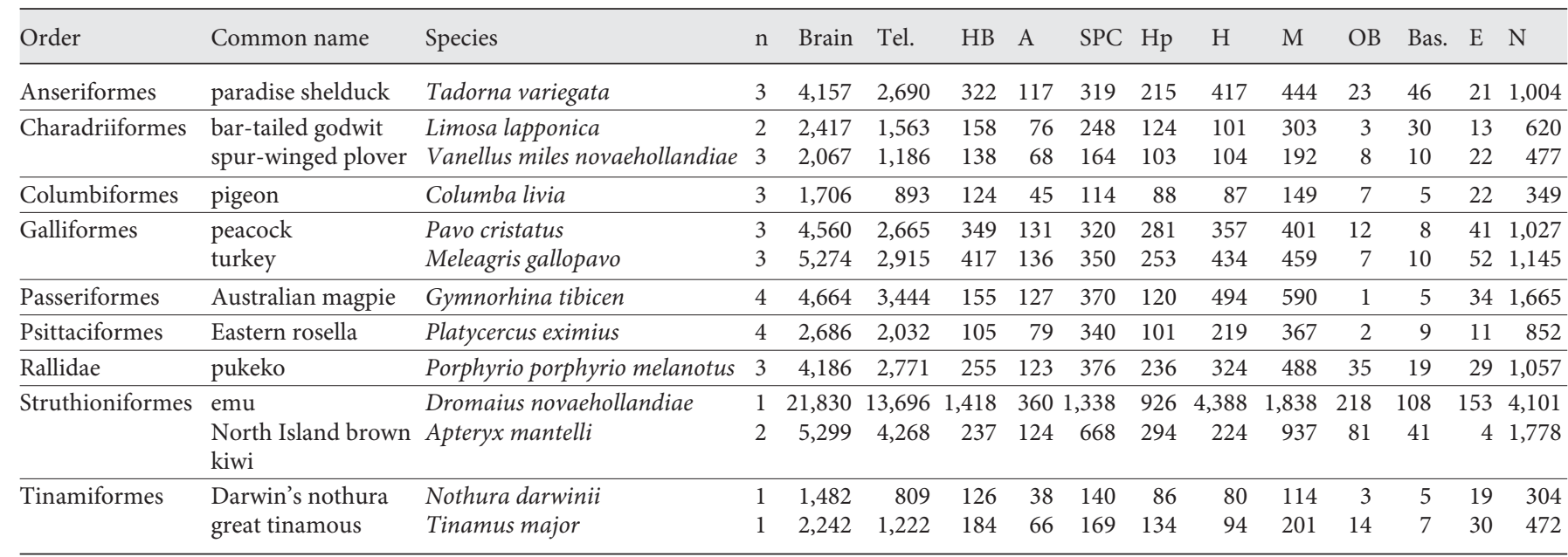

Tel. = Telencephalon; $\mathrm{HB}=$ hindbrain; $\mathrm{A}=$ arcopallium; $\mathrm{Hp}=$ hippocampus; $\mathrm{H}=$ hyperpallium; $\mathrm{M}=$ mesopallium; $\mathrm{OB}=$ olfactory bulb; $\mathrm{Bas} .=$ nucleus basorostralis; $\mathrm{E}=$ entopallium; $\mathrm{N}=$ nidopallium.

into left and right hemispheres, and cryoprotected in $30 \%$ sucrose. Each hemisphere was placed in a solution of $15 \%$ gelatine with $30 \%$ sucrose at $40^{\circ} \mathrm{C}$ for $1 \mathrm{~h}$. The brains were then placed into a custom-made mold so that fiduciary points could be made in the gelatine for later alignment of tissue sections. The mold consisted of a plastic base with small holes drilled in a grid pattern. The base of the mold was covered with $15 \%$ gelatine containing $30 \%$ sucrose in PBS and the gelatine was allowed to set. The brains were then placed on the gelatine base, with the midline facing down. Five to seven small pins were inserted into the holes that had been drilled in the base of the mold so that they surrounded the brain and ran in a rostral-caudal direction. A 15\% gelatine, 30\% sucrose and PBS solution containing black fabric dye (to darken the gelatine solution) was then poured over the brain. Once set, the gelatine block, including the brain, was removed, trimmed and placed, along with the pins, into $4 \%$ paraformaldehyde overnight. The pins were then removed and the block was sectioned on a sliding freezing microtome at $50-\mu \mathrm{m}$ thickness in the sagittal plane. Sections were collected in PBS-sodium azide $0.01 \%$. For each species, except for emu (Dromaius novaehollandiae), every second section was mounted serially onto gelatine chrome-alum-subbed slides, stained with cresyl violet, dehydrated and coverslipped with DePeX from xylene. For emu, every fourth section was processed because of the large size of the brain. Sections and fiduciary points in the surrounding gelatine were imaged using a Leica stereomicroscope, and the images subsequently loaded into AMIRA (v 5.2; Visage Imaging, San Diego, Calif., USA) for alignment and modeling as described below.

\section{D Modeling in AMIRA}

Individual images of the brain sections were loaded into AMIRA. An Alignslice module was attached to the data and each section was aligned according to the fiduciary points. A LabelField module was attached to the newly aligned image series and new materials were created to correspond with each brain region that was to be modeled. Each brain region was segmented out from each image using the brush tool and assigned its corresponding material. A small amount of label smoothing was undertaken to fine-tune the slice alignment. A SurfaceGen module was attached to the LabelField module and the $3 \mathrm{D}$ model was visualized by attaching a SurfaceView module.

Nine telencephalic regions were identified using boundary lines that could be recognized from the cresyl violet in the AMIRA stack. Boundaries were identified with the aid of sections stained for immunocytochemistry, namely the calcium-binding proteins calretinin, calbindin and parvalbumin (Swant, Bellinzona, Switzerland) and guided by several brain atlases [Karten and Hodos, 1967; Kuenzel and Masson, 1988; Puelles et al., 2007] and named according to the Consortium Nomenclature [Reiner et al., 2004]. Some examples of the telencephalic boundaries in 4 species of birds are shown in figure 1; the telencephalic boundary used is also shown in this study. The areas that were modeled were: olfactory bulb, the mesopallium (which included both dorsal and ventral subdivisions), nidopallium (excluding nucleus basorostralis or entopallium), arcopallium, entopallium, striatopallidal complex (SPC; mediale and laterale), nucleus basorostralis, hyperpallium (which included the Wulst components hyperpallium densocellulare, intercalatum and apicale, and the nucleus interstitialis hyperpallii apicalis) and hippocampus. Because the lateral boundary of the hippocampus was difficult to determine in sagittal sections, the caudodorsolateral pallium (CDL) was included in the hippocampus volume for all species. A volume was obtained for the hippocampus, but 3D models were not created. After the different brain regions were outlined in AMIRA, the stack of images was exported as a series of TIFF files. In these, a given region is filled in black against a white background. These TIFF stacks were then used for volumetric estimates of each region. All TIFF stacks were produced prior to the label smoothing that was applied to the 3-D models. 
Fig. 1. Photomicrographs of sagittal sections stained with cresyl violet through the brain of 4 species of birds. Top sections are more lateral and bottom sections more medial. The broken black lines indicate the borders of telencephalic regions and the broken and dotted black lines the boundary of the telencephalon. a North Island brown kiwi (Apteryx mantelli). b Eastern rosella ( $P$. eximius). c Emu (D. novaehollandiae). d Pigeon (Columba livia). A = Arcopallium; $\mathrm{N}=$ nidopallium; $\mathrm{H}=$ hyperpallium; Bas. = nucleus basorostralis; $\mathrm{E}=$ entopallium; $\mathrm{OB}=$ olfactory bulb; $\mathrm{Hp}=$ hippocampus; $\mathrm{M}=$ mesopallium. Scale bars $=5 \mathrm{~mm}$.

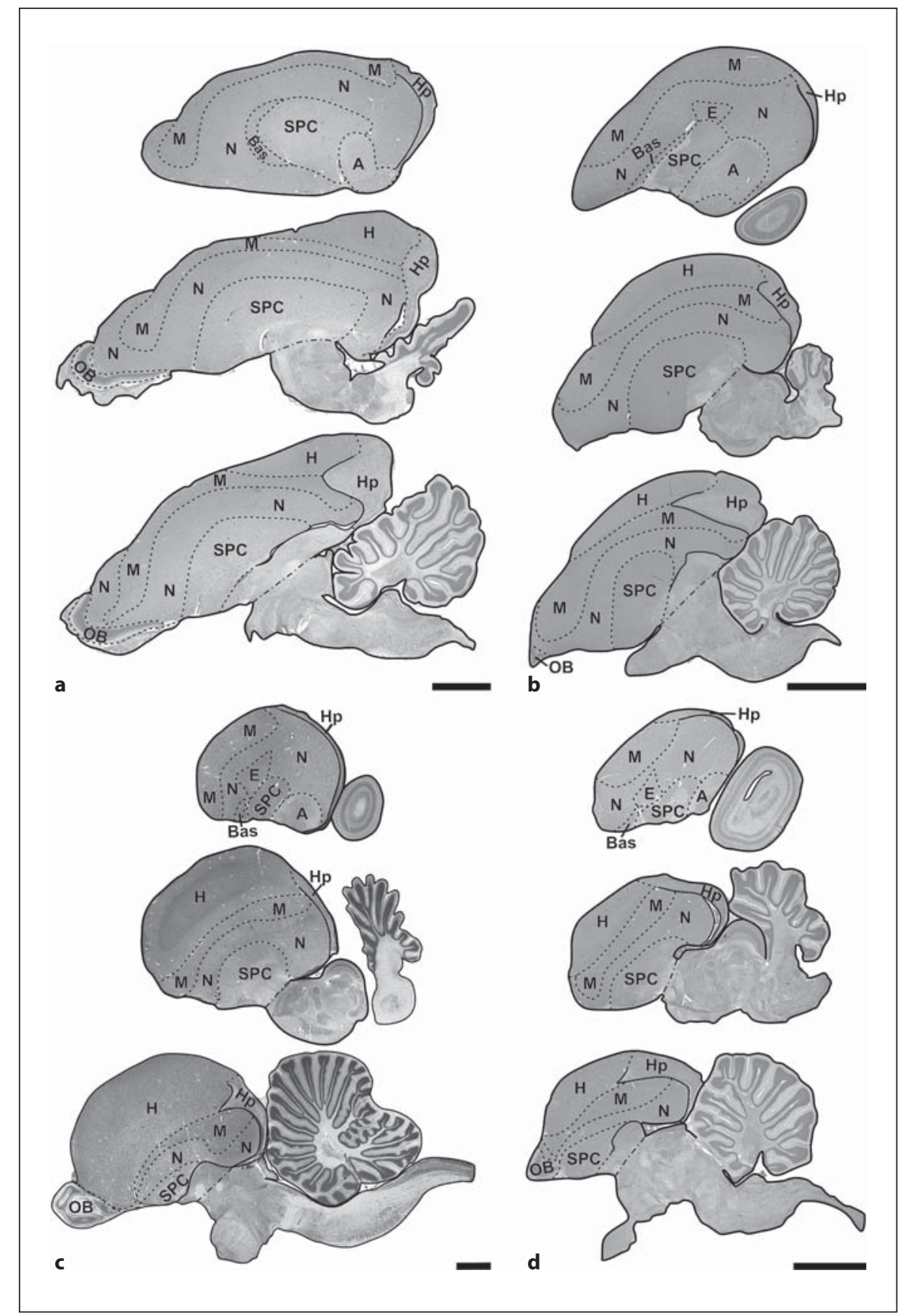

Volumetric Estimates of Brain Regions

The TIFF stacks from each brain region for each species created with AMIRA were loaded into ImageJ (National Institutes of Health, Bethesda, Md., USA; http://rsb.info.nih.gov/ij/) and calibrated using a microscope calibration scale bar. The images were thresholded to select the brain or brain region outlines. Each image was then analyzed to obtain the cross-sectional area of the brain object. To obtain the volumes, the cross-sectional areas were summed for each brain region and then multiplied by the slice thickness and the number of sections between stack slices, which for all species was $100 \mu \mathrm{m}$ except for the emu, for which it was $200 \mu \mathrm{m}$.

A major axis model II non-linear regression was performed using SPSS (v. 15, SPSS, Chicago, Ill., USA) and $h=r^{2} /\left(1+b^{2}\right)$ as the loss function (where $r$ is the residual and $b$ is the slope). All regressions were performed on $\log _{10}$-transformed data. Each brain region was regressed against 'telencephalon rest' volume (total telencephalon volume - brain region volume) to avoid Deacon's whole-part fallacy [Deacon, 1990] and against the hindbrain 
Table 2. Volumes of the telencephalon and 6 major telencephalic regions $\left(\mathrm{mm}^{3}\right)$ in both the left and right hemispheres

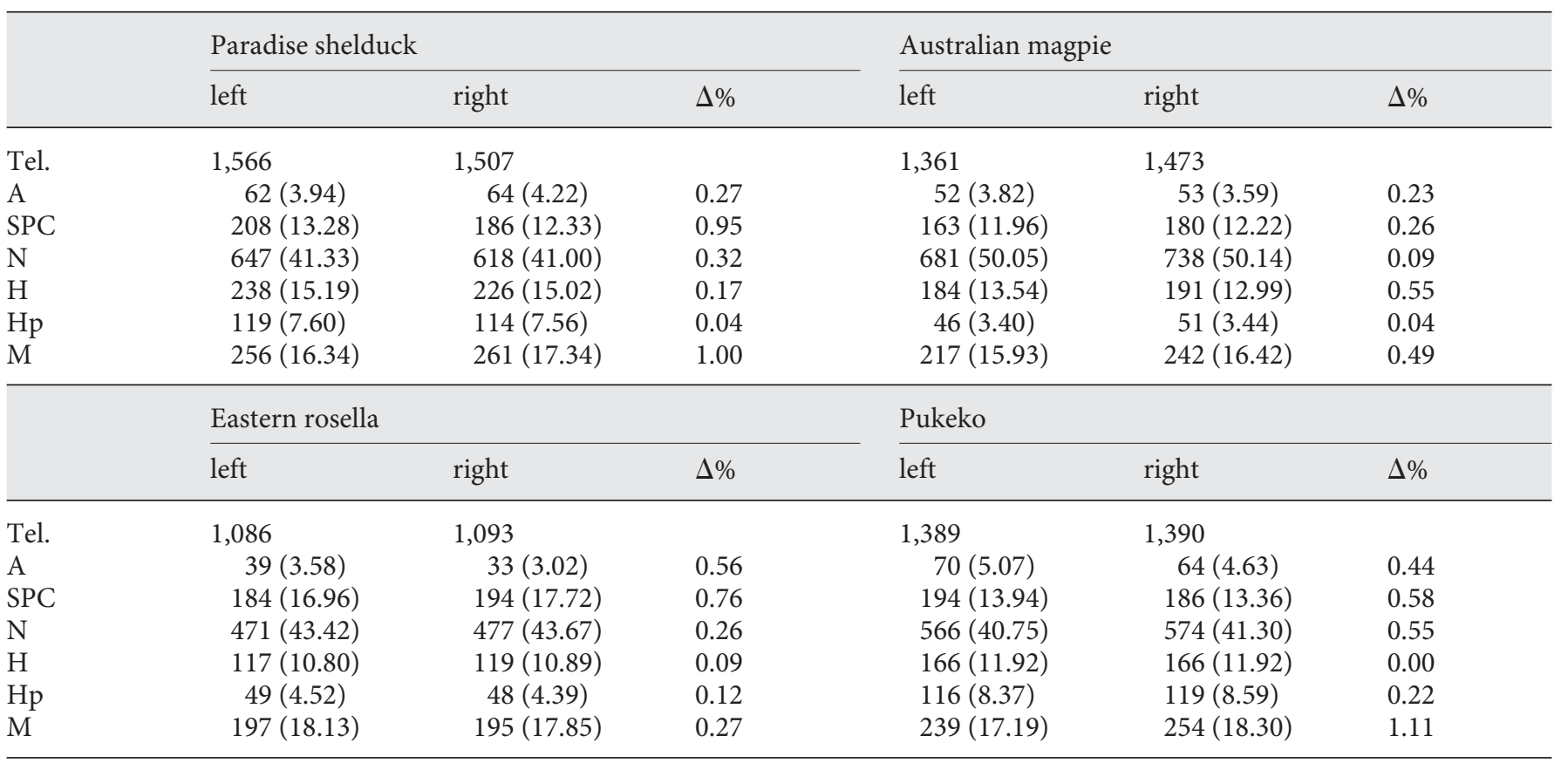

Numbers in parentheses correspond to the percentage of each structure with respect to the size of the hemisphere from which the percentage differences $(\Delta \%)$ were calculated. Data are from 1 specimen of each species. Tel. $=$ Telencephalon; $\mathrm{A}=$ arcopallium; $\mathrm{N}=$ nidopallium; $\mathrm{H}$ = hyperpallium; $\mathrm{Hp}$ = hippocampus; $\mathrm{M}$ = mesopallium.

volume (defined as rostral border of the isthmus to the caudal border of pseudorhombomere 11, as described by Puelles [2007], less the cerebellum). Regression against the hindbrain shows how the absolute size of the region varies, while regression against telencephalon rest shows how the proportion of the region varies within the telencephalon.

A region was considered to be hypertrophied or hypotrophied if the individual value fell outside the $95 \%$ confidence interval calculated from the regression slope. The confidence intervals were computed from the best-fit values from the non-linear regression and the standard error (SE) of those best-fit values using the following equation: BestFit $-t^{*}$ SE and BestFit $+t^{*} S E$, where $t$ is the critical value from the $t$ distribution.

Rather than to obtain volumes and create models for both hemispheres of the telencephalon, it was first determined whether there were any differences in the relative size of each region in the left versus right hemispheres in 4 species of birds. For all regions examined in all species, there was no more than a $1.1 \%$ difference between the left and right in the relative size of a specific region with respect to total size of the hemisphere (table 2). In the paradise shelduck (Tadorna variegata) and Australian magpie (Gymnorhina tibicen), the overall telencephalon size showed some variation between the left and right hemispheres (table 2). In the paradise shelduck, the left hemisphere was larger than the right (left: $1,566 \mathrm{~mm}^{3}$ vs. right: $1,507 \mathrm{~mm}^{3}$ ) and in the Australian magpie the right hemisphere was larger than the left (left: $1,361 \mathrm{~mm}^{3}$ vs. right: $1,473 \mathrm{~mm}^{3}$ ). Little variation occurred between the left

Telencephalic Structure in a Variety of Birds and right hemispheres in the Eastern rosella (Platycercus eximius; left: $1,086 \mathrm{~mm}^{3}$ vs. right: $1,093 \mathrm{~mm}^{3}$ ) and pukeko (Porphyrio porphyrio melanotus; left: $1,389 \mathrm{~mm}^{3}$ vs. right: $1,390 \mathrm{~mm}^{3}$; table 2). In summary, although there are some left/right asymmetries in the telencephalic hemispheres, the percentage that each region occupied within each hemisphere showed little or no difference in the 4 species examined. Therefore, apart from the paradise shelduck, Australian magpie, Eastern rosella and pukeko, volumes were only obtained from 1 hemisphere and then doubled.

\section{Results}

The Eastern rosella, the Australian magpie and kiwi all had relatively large telencephala compared to the other species (fig. 2; table 1). A relatively smaller telencephalic size was found in species belonging to the Galliformes (peacock and turkey) and Tinamiformes (Darwin's nothura and great tinamou). Overall, these species differences corroborate previous findings [Portmann, 1946; Rehkämper et al., 1991; Iwaniuk and Hurd, 2005; Corfield et al., 2008].

Every brain region showed hypertrophy in at least 1 species when the data were regressed against the hind- 


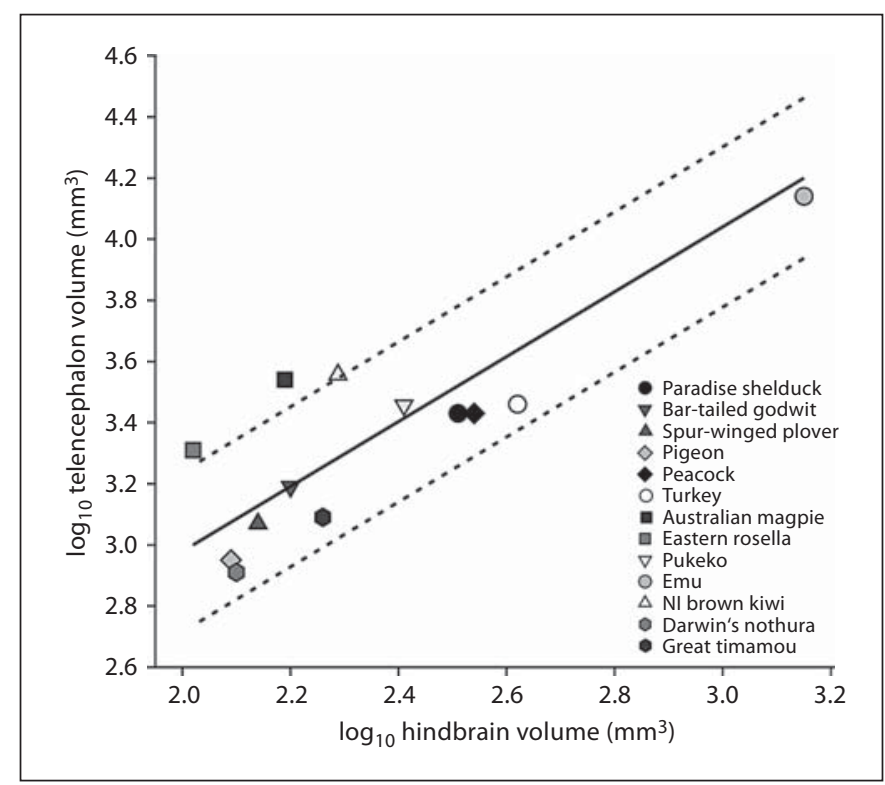

Fig. 2. Scatter plot of the volume of the telencephalon plotted as a function of hindbrain volume for all species examined. The solid line represents the regression line from the model II allometric analyses and the broken lines the $95 \%$ confidence intervals. NI = North Island.

brain volume. The arcopallium was hypertrophied in the Australian magpie and the Eastern rosella, and hypotrophied in Darwin's nothura (fig. 3a). The SPC was hypertrophied in the Australian magpie, Eastern rosella and kiwi, and hypotrophied in the pigeon, great tinamou, peacock and turkey (fig. 3b). The hippocampus/CDL was hypertrophied in the kiwi, but no hypertrophy or hypotrophy of this structure was seen in any of the other species (fig. 3c). The mesopallium was hypertrophied in the Australian magpie, the Eastern rosella and the kiwi, and hypotrophied in Darwin's nothura, great tinamou, emu, peacock and turkey (fig. 3d). The hyperpallium was hypertrophied in the Australian magpie and Eastern rosella, and hypotrophied only in the great tinamou (fig. 3e). The olfactory bulb was hypertrophied in the pigeon, spur-winged plover, pukeko, great tinamou and kiwi, and hypotrophied in the Australian magpie, peacock, turkey and emu (fig. 3f). The nidopallium was hypertrophied in the Australian magpie, Eastern rosella, and kiwi, and hypotrophied in Darwin's nothura and great tinamou (fig. 3g). The nucleus basorostralis was hypertrophied in Eastern rosella, paradise shelduck, bar-tailed godwit and kiwi, and hypotrophied in the emu, turkey and peacock (fig. 3h). The entopallium was hypertrophied in the pigeon and Australian magpie, but hypotrophied in kiwi, emu and turkey (fig. 3i). Overall, when the data were regressed against the hindbrain, the SPC, olfactory bulb, nidopallium, nucleus basorostralis and entopallium showed the greatest degree of variation between species.

To determine the degree to which the volume of each region co-varied with the changes in overall telencephalic volumes, data for each region were regressed against the telencephalon - the telencephalic region (see Materials and Methods), and less extent of variation was seen (fig. 4). All volumes fell inside the $95 \%$ confidence interval in the SPC and the mesopallium (fig. 4b, d). In the arcopallium and hyperpallium, only the kiwi showed hypotrophy (fig. 4a, e). The hippocampus/CDL of the Australian magpie and Eastern rosella showed hypotrophy, while the values for all other species fell inside the $95 \%$ confidence interval (fig. 4c). The olfactory bulb was hypertrophied in Darwin's nothura, great tinamou, pigeon and spur-winged plover, and hypotrophied in the Australian magpie, Eastern rosella and emu (fig. 4f). The Australian magpie was the only species to show hypertrophy of the nidopallium (fig. 4g). The nucleus basorostralis was hypertrophied in the bar-tailed godwit, spur-winged plover and paradise shelduck, and hypotrophied in the peacock, turkey and Australian magpie (fig. 4h). Finally, the entopallium was hypertrophied in Darwin's nothura, great tinamou, pigeon and spur-winged plover, and hypotrophied in the emu, kiwi and Eastern rosella (fig. 4i). The greatest extent of relative size variation when data were regressed against telencephalic volume was seen in the olfactory bulb, entopallium and nucleus basorostralis. The proportion that each of the regions occupies in the telencephalon is shown in figure 5 .

When regressed against either the hindbrain or telencephalon - the telencephalic region volume, the emu, peacock and turkey only showed hypotrophy of specific telencephalic regions, while the paradise shelduck, bartailed godwit, spur-winged plover and pukeko only showed hypertrophy of telencephalic regions. For all other species, both hypertrophy and hypotrophy were seen. The kiwi showed no hypertrophy of any brain region when the data were regressed against telencephalic size, suggesting that no specific region is enlarged beyond that expected from the overall enlargement of the telencephalon. The same is true for the Eastern rosella. In contrast, in the Australian magpie, the nidopallium is enlarged beyond that expected from the enlargement of the telencephalon as a whole. Other specific enlargements beyond those expected from the enlargement of the telencephalon as a whole include the olfactory bulb in the pigeon, the spur-winged plover, the great tinamou and Darwin's 


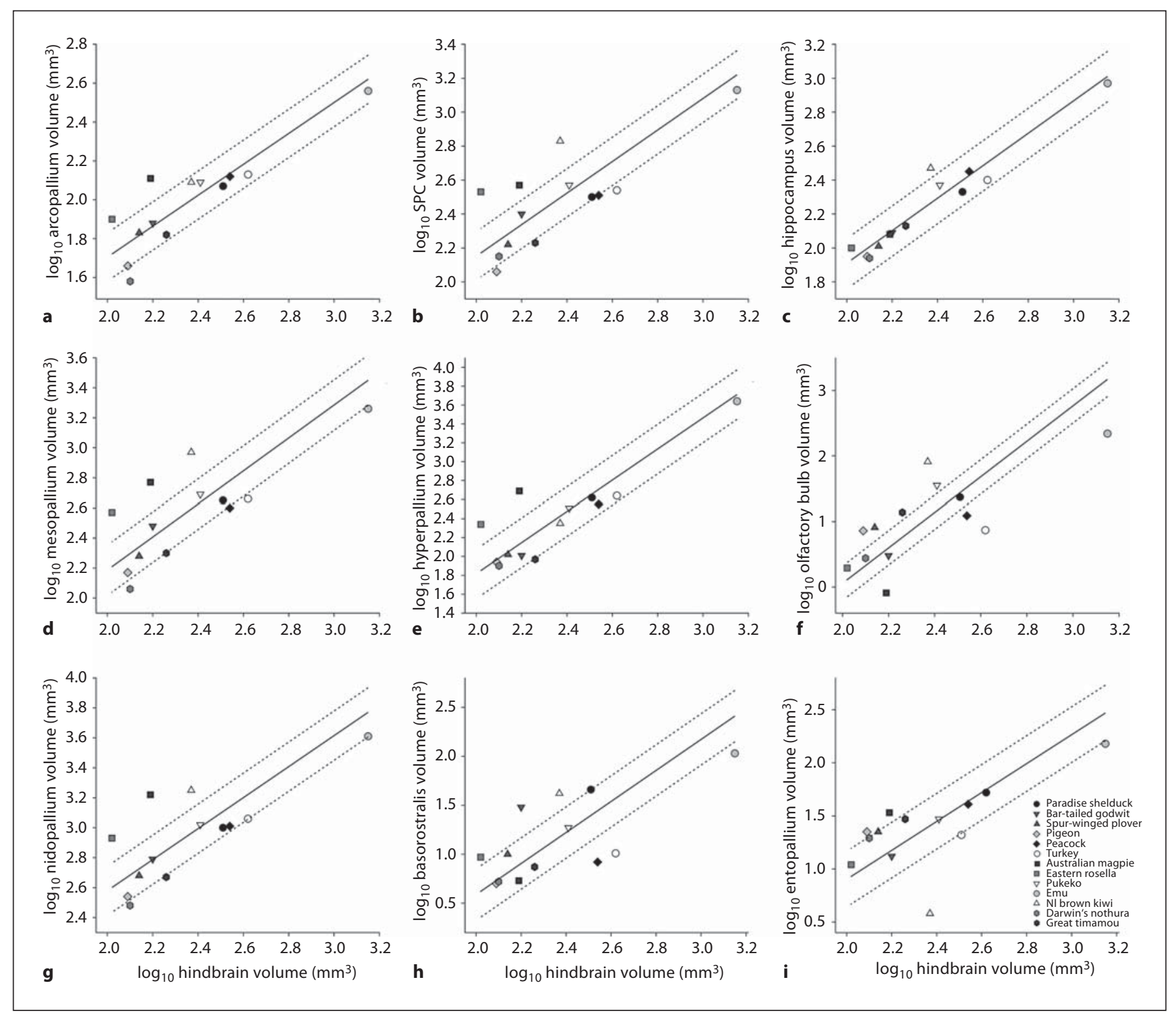

Fig. 3. Scatter plot of the volume of 9 telencephalic regions plotted as a function of hindbrain volume for all species examined. a Arcopallium. b SPC. c Hippocampus. d Mesopallium. e Hyperpallium. f Olfactory bulb. $\mathbf{g}$ Nidopallium. h Nucleus basorostralis. i Entopallium. The solid line represents the regression line from the model II allometric analyses and the broken lines the 95\% confidence intervals. $\mathrm{NI}=$ North Island. nothura, the nucleus basorostralis in the paradise shelduck and bar-tailed godwit, and the entopallium in the pigeon, spur-winged plover, great tinamous and Darwin's nothura. Regions that were smaller than expected from telencephalic size included the arcopallium, entopallium and hyperpallium in the kiwi, the hippocampus/CDL in the Australian magpie and Eastern rosella, the olfactory bulb in the emu, Australian magpie and Eastern rosella, nucleus basorostralis in the Australian magpie, peacock and turkey, and the entopallium in the emu and Eastern rosella. It seems, therefore, that the relative variation in size of specific structures is not specific to particular phylogenetic lineages, and that hypertrophy and hypotrophy can be found in both Palaeognath and Neognath birds.

Given the inhomogeneous variation of different telencephalic nuclei, we examined the proportion of volume 


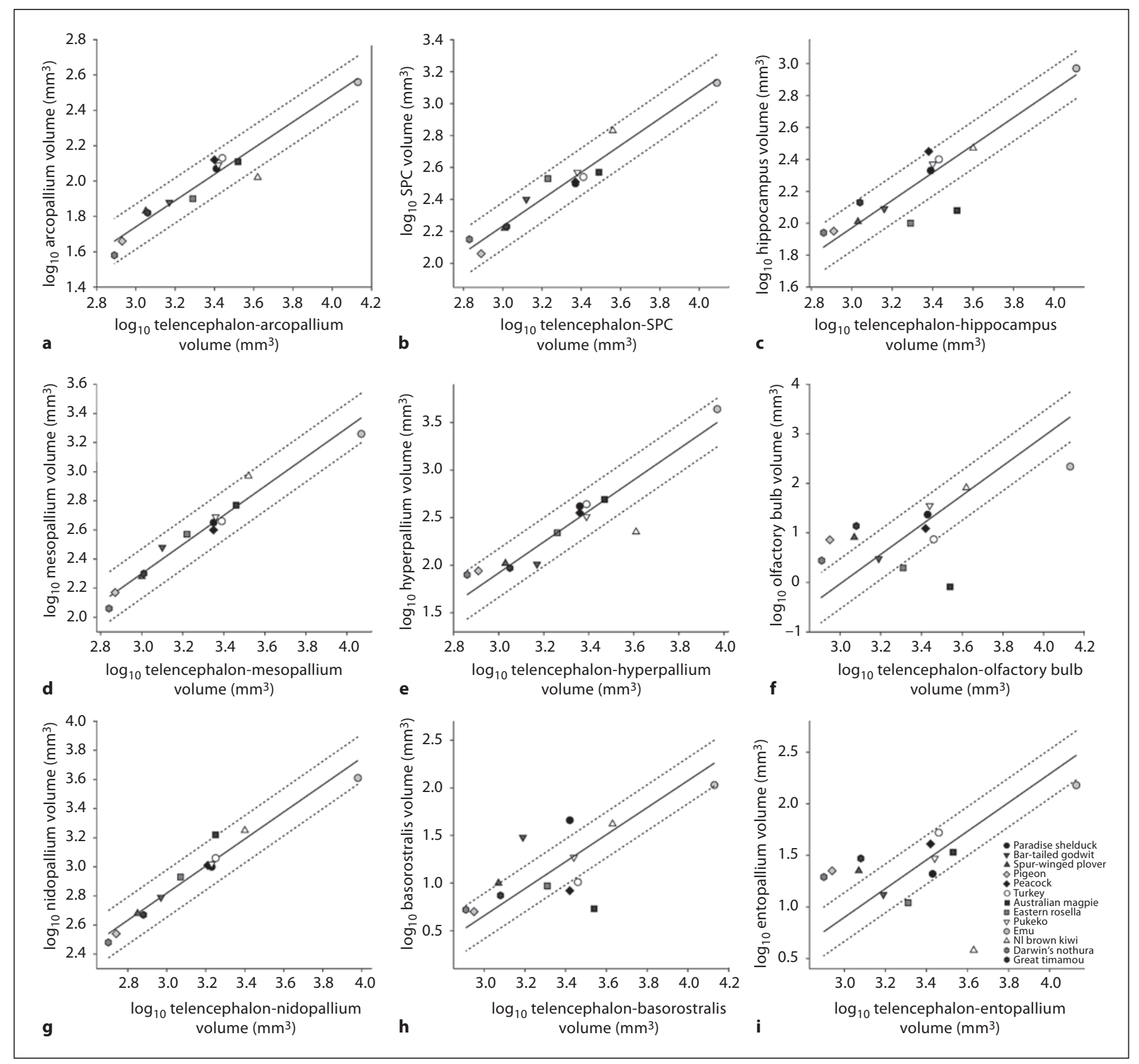

Fig. 4. Scatter plot of the volume of 9 telencephalic regions plotted as a function of the volume of the telencephalon minus the region of interest for all species examined. a Arcopallium. b SPC. c Hippocampus. d Mesopallium. e Hyperpallium. f Olfactory bulb.

that each nucleus occupied in the telencephalon (fig. 5; table 3). In kiwi, the proportions of the mesopallium (22.0\%) and olfactory bulb (1.9\%) are the greatest of any of the birds examined, whereas the hyperpallium (5.3\%) is the least. The proportions of telencephalic regions in the emu are considerably different from those of all other g Nidopallium. h Nucleus basorostralis. i Entopallium. The solid line represents the regression line from the model II allometric analyses and the broken lines the $95 \%$ confidence intervals. NI = North Island. 


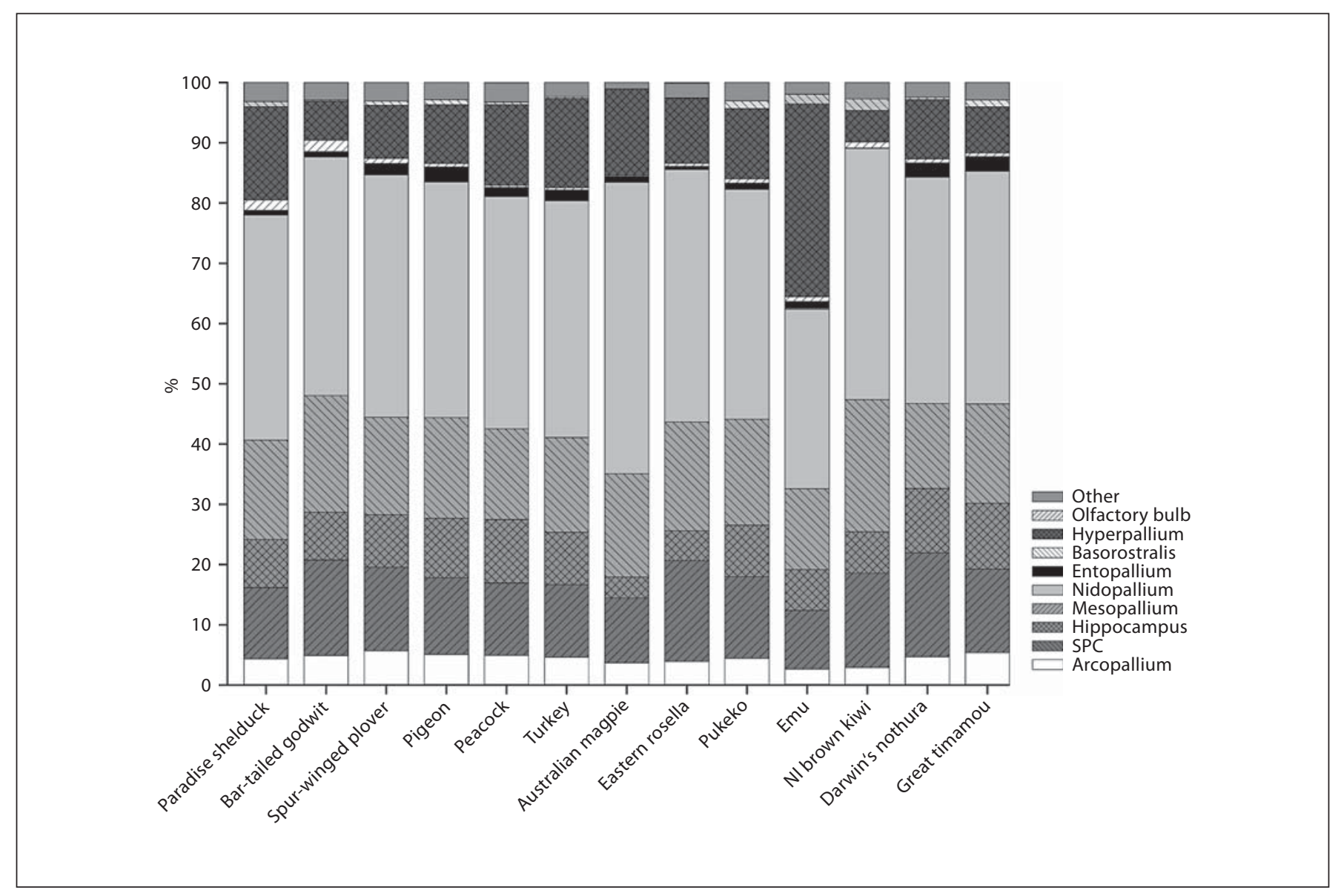

Fig. 5. The volume of arcopallium, SPC, hippocampus, mesopallium, nidopallium, entopallium, hyperpallium, nucleus basorostralis and the rest of the telencephalon plotted as a percentage of the telencephalon. NI = North Island.

Table 3. Volumes of the arcopallium (A), SPC, hippocampus (Hp), hyperpallium (H), mesopallium (M), olfactory bulb (OB), nucleus basorostralis (Bas), entopallium (E), nidopallium (N) and the rest of the telencephalon (other) as a percentage of the telencephalon

\begin{tabular}{|c|c|c|c|c|c|c|c|c|c|c|c|c|}
\hline Order & Common name & Species & A & SPC & Hp & $\mathrm{H}$ & M & $\mathrm{OB}$ & Bas. & $\mathrm{E}$ & $\mathrm{N}$ & Other \\
\hline Anseriformes & paradise shelduck & Tadorna variegata & 4.3 & 11.9 & 8.0 & 15.5 & 16.5 & 0.9 & 1.7 & 0.8 & 37.3 & 3.1 \\
\hline \multirow[t]{2}{*}{ Charadriiformes } & bar-tailed godwit & Limosa lapponica & 4.9 & 15.9 & 7.9 & 6.5 & 19.4 & 0.2 & 1.9 & 0.8 & 39.6 & 2.9 \\
\hline & spur-winged plover & Vanellus miles novaehollandiae & 5.7 & 13.9 & 8.7 & 8.8 & 16.2 & 0.7 & 0.8 & 1.9 & 40.2 & 3.1 \\
\hline Columbiformes & pigeon & Columba livia & 5.1 & 12.7 & 9.9 & 9.7 & 16.7 & 0.8 & 0.6 & 2.5 & 39.1 & 2.9 \\
\hline Galliformes & peacock & Pavo cristatus & 4.9 & 12.0 & 10.6 & 13.4 & 15.0 & 0.5 & 0.3 & 1.5 & 38.5 & 3.2 \\
\hline Psittaciformes & Eastern rosella & Platycercus eximius & 3.9 & 16.7 & 5.0 & 10.8 & 18.1 & 0.1 & 0.5 & 0.5 & 41.9 & 2.5 \\
\hline Rallidae & pukeko & Porphyrio porphyrio melanotus & 4.5 & 13.6 & 8.5 & 11.7 & 17.6 & 1.3 & 0.7 & 1.1 & 38.1 & 3.0 \\
\hline \multirow[t]{2}{*}{ Struthioniformes } & emu & Dromaius novaehollandiae & 2.6 & 9.8 & 6.8 & 32.0 & 13.4 & 1.6 & 0.8 & 1.1 & 29.9 & 1.9 \\
\hline & $\begin{array}{l}\text { North Island brown } \\
\text { kiwi }\end{array}$ & Apteryx mantelli & 2.9 & 15.7 & 6.9 & 5.3 & 22.0 & 1.9 & 1.0 & 0.1 & 41.7 & 2.7 \\
\hline
\end{tabular}




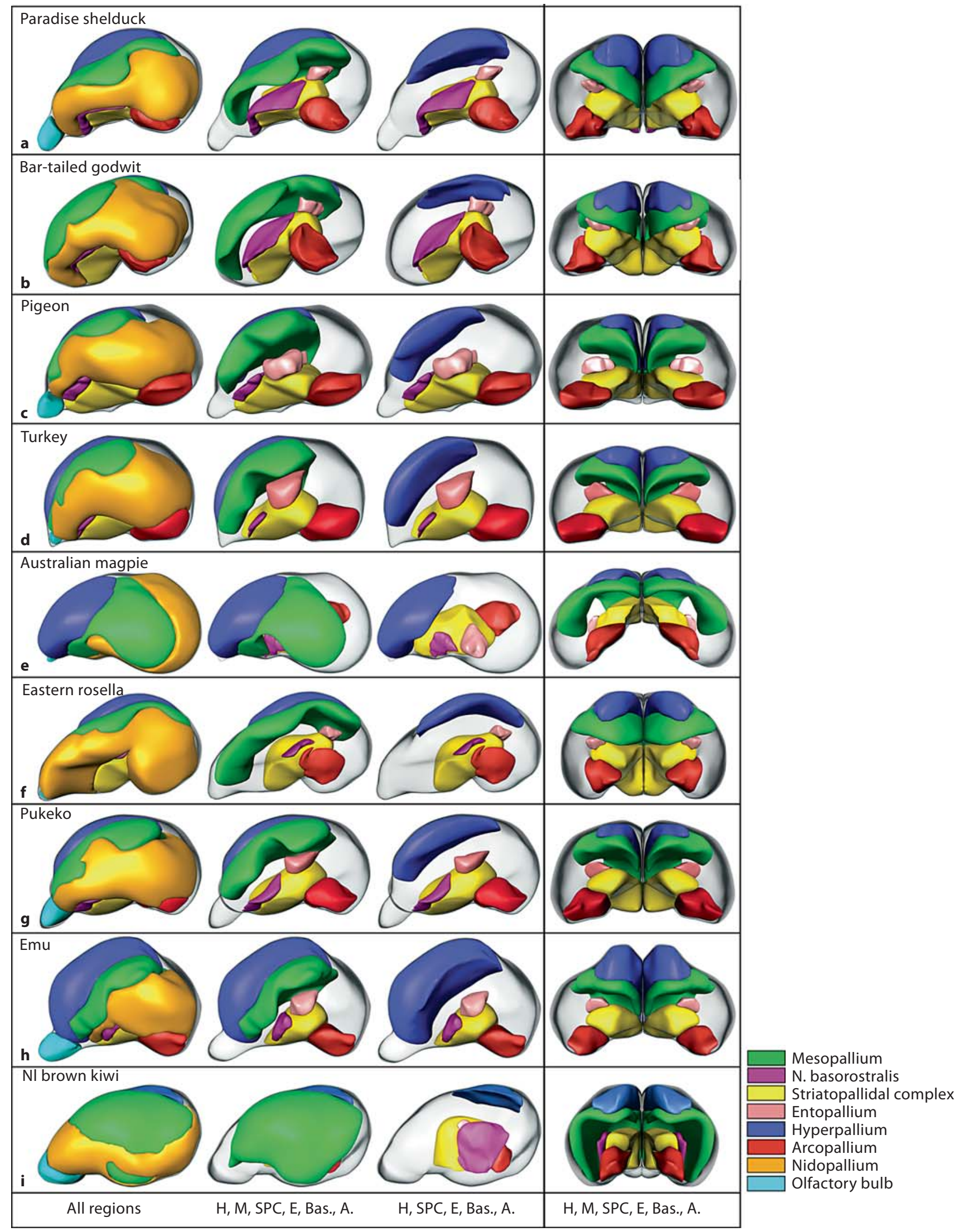


tion of nidopallium (48.4\%) and the Eastern rosella a relatively high SPC (16.7\%) and mesopallium (18.1\%, fig. 5; table 3) proportion.

\section{Morphology}

Kiwi showed a rostral expansion of the telencephalon, due to an expansion of either the nidopallium or mesopallium (fig. 6; online suppl. fig. 3; for all suppl. material, see www.karger.com/doi/10.1159/000339828). This is also the case in the bar-tailed godwit, paradise shelduck and Eastern rosella (fig. 6; online suppl. fig. 1,2). The mesopallium in kiwi extends throughout the rostrocaudal extent of the telencephalon and nearly to its ventral border, especially at the caudal pole (fig. 6; online suppl. fig. 3). It forms a relatively thin sheet that for the most part surrounds the entire nidopallium, and shows expansions at both the rostrocaudal and dorsoventral ends. In the magpie, the mesopallium shows a similar ventral expansion, although it does not extend to the caudal extremes as it does in the kiwi (fig. 6; online suppl. fig. 2). In the other birds examined, the mesopallium only occupies a dorsomedial strip ventral to the hyperpallium. The hyperpallium in kiwi is restricted to a caudal location, and this is also true to a lesser extent in the godwit and Eastern rosella (fig. 6; online suppl. fig. 1-3). In these birds, the hyperpallium does not show the rostral extension found in the other birds examined. In contrast, the emu (the closest relative of the kiwi) shows a massive rostral expansion of the hyperpallium (fig. 6; online suppl. fig. 3). Similarly, but not as extreme, the magpie also shows a rostral expansion of the hyperpallium, but it also extends further laterally (fig. 6; online suppl. fig. 2). The 3D structure of SPC and arcopallium was quite variable between species (fig. 6; online suppl. fig. 1-3).

Fig. 6. Lateral and caudal views of $3 \mathrm{D}$ reconstructions of the telencephalon and 8 telencephalic regions in 9 species of birds. The telencephalon is displayed as a transparent object while the telencephalic regions are colored as shown in the legend. The three lateral views for each species are first displayed with all regions and then without the nidopallium and olfactory bulb, and then with the mesopallium removed. This allows all regions to be visualized. Caudal views are also shown for each species. Species for which models are shown: a Paradise shelduck (Tadorna variegata). b Bar-tailed godwit (Limosa lapponica). c Rock pigeon (C. livia). d Turkey (Meleagris gallopavo). e Australian magpie (G. tibicen). $\mathbf{f}$ Eastern rosella (P. eximius). g Pukeko (P. porphyrio melanotus). $\mathbf{h} \mathrm{Emu}$ (D. novaehollandiae). i North Island brown kiwi (A. mantelli). A = Arcopallium; $\mathrm{H}$ = hyperpallium; Bas. = nucleus basorostralis; $\mathrm{E}=$ entopallium; $\mathrm{M}=$ mesopallium.

Telencephalic Structure in a Variety of Birds

\section{Discussion}

Our results suggest that in the bird species studied, changes in the relative size of telencephalic regions are not homogeneous. All species showed hypertrophy or hypotrophy of at least one telencephalic region. In addition, some species in this study showed morphological variations of the telencephalic regions examined, either in their rostrocaudal and mediolateral extent or in the relative position they occupy.

Of the 9 telencephalic regions examined, the mesopallium, nidopallium and SPC make up the majority of the telencephalon. Although we are only beginning to understand some of the functions of these regions, they have been associated with a wide range of behaviors. Enlargements of these regions are characteristic of some parrots (Psittaciformes) and songbirds (Passeriformes), including corvids, in which they are thought to reflect a high level of cognition, allowing them to perform complex tasks, such as vocal learning and tool manufacture [Hunt, 1996; Clayton and Dickinson, 1998; Weir et al., 2002; Emery and Clayton, 2004; Emery, 2006; Huber and Gajdon, 2006; Raby et al., 2007; Prior et al., 2008; Seed et al., 2008, 2009]. In addition, the mesopallium has been associated with innovative feeding behaviors [Timmermans et al., 2000] and vocal perception/production [Gentner et al., 2000; Plummer and Striedter, 2002]. SPC is thought to be involved in the control of stereotyped, species-specific behavioral responses [Reiner et al., 1984; Dubbeldam, 1998] and has also been implicated in learning [Parent, 1986; Scharff and Nottebohm, 1991; Stewart et al., 1996; Csillag, 1999; Mezey et al., 1999; Watanabe, 2001].

These studies have undoubtedly provided insights into the functions of these regions, but because brains are not functionally organized on a one-function/one-region basis, but as dynamic, functionally interactive systems to which particular subregions contribute in specific ways in different contexts [Feenders et al., 2008], conclusions about the implications for behavior of a specific enlargement or reduction of a central structure must be drawn with extreme caution. In the present study, we were constrained to draw on knowledge of behavior, ecology and physiology for the species examined to make tentative suggestions as to the reason or reasons for an enlargement or reduction in size of a region.

As an example, consider the behavior of the kiwi, a nocturnal, flightless species that is adapted to occupying a ground-dwelling niche. Correspondingly, the organization of its telencephalon differed in many respects from

Brain Behav Evol 2012;80:181-195 
that of the other species examined in this study. Contributing to its enlarged telencephalon was an enlarged SPC, mesopallium, nucleus basorostralis, hippocampus/CDL, olfactory bulb and nidopallium, but not arcopallium, hyperpallium or entopallium. Why this particular suite of structural enlargements is present in kiwi is not altogether clear, but it can be noted that the bird seems to rely heavily on olfaction for locating food items [Wenzel, $1968,1971]$. Although comparatively little is known about the functional organization of the avian 'olfactory brain' in pigeons, projections from the olfactory bulb have been found throughout extensive regions of the telencephalon, including piriform cortex, mesopallium, medial striatum, globus pallidus, septum, nucleus taeniae of the amygdala and the dorsomedial hippocampus [Rieke and Wenzel, 1978; Reiner and Karten, 1985; Teuchert et al., 1986]. Several of these structures in kiwi are likely involved in processing olfactory information from the massive olfactory bulb, perhaps thereby accounting for their relative enlargement.

Among the species examined in the present study were those that likely rely heavily on tactile information from the beak and tongue. These species consist of the kiwi, bar-tailed godwit, Eastern rosella and paradise shelduck, and all have been shown to have a specialized arrangement of mechanoreceptors within pits at the bill tip and/ or in the tongue [Cunningham et al., 2007; Martin et al., 2007]. Both kiwi and bar-tailed godwit, like many shorebirds, rely on this tactile sense for detecting and selecting food beneath the ground, ducks for detection, recognition, and transportation of food in the mouth, and parrots for complex manipulations of food items. In all these species, and likely accompanying these specialization of the beak and tongue, is the relatively enlarged nucleus basorostralis, which processes information from these peripheral structures via the principal sensory trigeminal nucleus [Witkovsky et al., 1973; Berkhoudt et al., 1981; Dubbeldam et al., 1981; Wild, 1985; Dubbeldam, 1990; Wild and Farabaugh, 1996; Wild et al., 2001]. The bartailed godwit and kiwi also share a caudal displacement of the hyperpallium, but the significance of this remains speculative. Since the hyperpallium is largely visual in nature, its caudal displacement could indicate a reduction in the importance of vision, as in kiwi [Martin et al., 2007]. But in most other avian species the hyperpallium extends to the rostral pole of the brain caudal to the olfactory bulbs, and its most rostral, minor part - the so-called rostral Wulst - is somatosensory in nature, receiving projections via the thalamus from parts of the body other than the beak [Wild, 1987; Funke, 1989; Wild, 1997; Wild et al., 2008]. In kiwi, bar-tailed godwit, Eastern rosella and paradise shelduck, there is a massive rostral expansion of the frontal part of the telencephalon, but whether this region processes information from the beak and tongue and/or from other parts of the body is unknown [Stingelin and Senn, 1969; Pettigrew and Frost, 1985].

It is interesting to note that within the species that showed enlarged telencephalon, some regions did not enlarge with the rest of the telencephalon and some even appear to be smaller than expected. This is particularly true for the kiwi, in which the arcopallium and hyperpallium did not accompany the enlargement of the telencephalon, and the entopallium appeared to have reduced in size. The small size of the hyperpallium (visual and perhaps somatosensory Wulst) in kiwi is in contrast to that reported for other nocturnal species and is unlike that of its closest relative, the emu. Nocturnal owls, such as the boobook owl (Ninox boobook), Northern saw-whet owl (Aegolius acadicus) and barn owl (Tyto alba), show enlargement of the visual Wulst [Iwaniuk and Hurd, 2005; Iwaniuk et al., 2008], the primary telencephalic representation of the thalamofugal system [Güntürkün et al., 1993; Shimizu and Karten, 1993]. The most extreme hypotrophy in kiwi was seen in the entopallium, the end station of the tectofugal visual pathway. The small relative size of the hyperpallium and entopallium in kiwi is likely commensurate with the suggested reduction in the reliance on vision. Kiwi have small eyes, a small optic nerve and optic tectum and small visual fields, including a reduced frontal binocular field [Martin et al., 2007]. Similar to the hyperpallium, the arcopallium in kiwi has not increased in size relative to the hindbrain, and thus did not contribute to the enlargement of the telencephalon. Since visual output from the entopallium, in particular, reaches the arcopallium, the reduction in size of the latter in kiwi could also reflect a reduction in the functional importance of vision.

Also noteworthy is that the only region that did not accompany the telencephalic enlargement in the Eastern rosella and Australian magpie was the hippocampus. The hippocampus has been the focus of many studies and has been shown to be essential to learning and memory, with variations in size correlating with tasks involving an extra demand for spatial learning and memory [Krebs et al., 1989; Sherry et al., 1989; Healy and Krebs, 1992; Basil et al., 1996; Healy and Krebs, 1996; Clayton, 1998; Biegler et al., 2001]. The hippocampus is also interesting because hippocampal neurons are continually produced in birds through adult neurogenesis [Barnea and Nottebohm, 1994]. Why the hippocampus did not enlarge with the 
rest of the telencephalon in the Eastern rosella and Australian magpie, as it did in the kiwi, is unknown, but these differences may reflect an enhanced reliance on learning and memory in the kiwi, or possibly differences in adult neurogenesis between the species. Unfortunately, it was not possible to include species in this data set that have been shown to have enhanced spatial learning and memory abilities to further examine variations in hippocampus size in birds.

The most interesting morphological feature of a region in the telencephalon was the rostrocaudal and dorsoventral expansion of the mesopallium in the kiwi. The mesopallium contributed to the enlargement of the telencephalon, but not beyond that expected from scaling to the telencephalon. It is not clear whether the changes in overall architecture of the mesopallium may represent differential growth of particular nuclei within the region, and if so, whether these are associated with particular behaviors. Alternatively, the changes in 3D shape could simply be the result of a reorganization of the different brain regions to adjust to the hypotrophy of the arcopallium, hyperpallium and entopallium.

Overall, this study has shown that the relative size and morphology of telencephalic areas is not homogeneous across birds, and large differences can be seen between closely related species such as the kiwi and emu. Many of the enlargements and reductions of telencephalic regions seen in this study likely reflect the animal's behavior, ecology or physiology. This is especially true for regions, such as the entopallium, that are known to play a major role in vision, but is less clear for regions such as the mesopallium, due to the multiple sensory representations of the latter and its apparent role in a variety of different behaviors. Nevertheless, the results provide further evidence of mosaic evolution and highlight the importance of the environment in shaping the brain organization of birds.

\section{Acknowledgments}

The authors would like to thank the New Zealand Department of Conservation for their support during this project, particularly C. Gardner and P. Graham for their invaluable assistance in obtaining kiwi specimens. We are also grateful to B. Gartrell at the Massey University College of Veterinary Medicine, B. Gill and the Auckland Museum, and R. Pennell at Northland Ostrich and Emu Ltd for their assistance in procuring specimens. Thanks are also due to A. Iwaniuk for helpful comments on an earlier version of this paper.

\section{References}

Aboitiz F (1996): Does bigger mean better? Evolutionary determinants of brain size and structure. Brain Behav Evol 47:225-245.

Bang BG, Cobb S (1968): The size of the olfactory bulb in 108 species of birds. Auk 85:55-61.

Barnea A, Nottebohm F (1994): Seasonal recruitment of hippocampal neurons in adult freeranging black-capped chickadees. Proc Natl Acad Sci USA 91:11217-11221.

Barton RA (1996): Neocortex size and behavioural ecology in primates. Proc Biol Sci 263: 173-177.

Barton RA, Harvey PH (2000): Mosaic evolution of brain structure in mammals. Nature 405: 1055-1058.

- Basil JA, Kamil AC, Balda RP, Fite KV (1996): Differences in hippocampal volume among food storing corvids. Brain Behav Evol 47: 156-164.

Bennett P, Harvey P (1985): Relative brain size and ecology in birds. J Zool Lond (A) 207 151-169.

Berkhoudt H, Dubbeldam JL, Zeilstra S (1981): Studies on the somatotopy of the trigeminal system in the mallard, Anas platyrhynchos L. IV. Tactile representation in the nucleus basalis. J Comp Neurol 196:407-420.
Biegler R, McGregor A, Krebs JR, Healy SD (2001): A larger hippocampus is associated with longer-lasting spatial memory. Proc Natl Acad Sci USA 98:6941-6944.

Clack D, Mitra P, Wang S (2001): Scalable architecture of mammalian brains. Nature 411 : 189-193.

Clayton N (1998): Memory and the hippocampus in food-storing birds: a comparative approach. Neuropharmacology 37:441-452.

Clayton NS, Dickinson A (1998): Episodic-like memory during cache recovery by scrub jays. Nature 395:272-274.

Cluttonbrock TH, Harvey PH (1980): Primates, brains and ecology. J Zool 190:309-323.

Cnotka J, Gunturkun O, Rehkamper G, Gray RD, Hunt GR (2008): Extraordinary large brains in tool-using New Caledonian crows (Corvus moneduloides). Neurosci Lett 433: 241-245.

Cobb S (1960): A note on the size of the avian olfactory bulb. Epilepsia 1:394-402.

Cobb S (1964): A comparison of the size of an auditory nucleus (n. mesensephalicus lateralis, pars dorsalis) with the size of the optic lobe in twenty seven species of birds. J Comp Neurol 122:271-279.
Corfield JR (2009): Evolution of the brain and sensory systems of the kiwi. PhD thesis, Auckland, University of Auckland.

Corfield JR, Kubke MF, Parsons S, Wild JM, Köppl C (2011): Evidence for an auditory fovea in the New Zealand kiwi (Apteryx mantelli). PLoS One 6:e23771.

Corfield JR, Wild JM, Hauber ME, Parsons S, Kubke MF (2008): Evolution of brain size in the Palaeognath lineage, with an emphasis on New Zealand ratites. Brain Behav Evol 71: 87-99.

Csillag A (1999): Striato-telencephalic and striato-tegmental circuits: relevance to learning in domestic chicks. Behav Brain Res 98:227236.

Cunningham SJ, Castro I, Alley M (2007): A new prey-detection mechanism for kiwi (Apteryx spp.) suggests convergent evolution between paleognathous and neognathous birds. J Anat 211:493-502.

Cunningham SJ, Castro I, Potter MA (2009): The relative importance of olfaction and remote touch in prey detection by North Island brown kiwis. Anim Behav 78:899-905 
Deacon TW (1990): Fallacies of progression in theories of brain-size evolution. Int J Primatol 11:193-236.

-Devoogd T, Krebs J, Healy S, Purvis A (1993): Relations between the song repertoire size and the volume of brain nuclei related to song: comparative evolutionary analyses amongst oscine birds. Proc R Soc Lond B Biol Sci 254:75-82.

de Winter W, Oxnard CE (2001): Evolutionary radiations and convergences in the structural organization of mammalian brains. $\mathrm{Na}$ ture 409:710-714.

Dubbeldam JL (1990): On the functional interpretation of quantitative differences in forebrain organization - the trigeminal and visual system in birds. Neth J Zool 40:241-253.

Dubbeldam JL (1998): Birds; in Nieuwenhuys R, ten Donkelaar H, Nicholson C (eds): The Central Nervous System of Vertebrates. Heidelberg, Springer, vol 3, pp 1525-1636.

Dubbeldam JL, Brauch CS, Don A (1981): Studies on the somatotopy of the trigeminal system in the mallard, Anas platyrhynchos L. III. Afferents and organization of the nucleus basalis. J Comp Neurol 196:391-405.

-Emery NJ (2006): Cognitive ornithology: the evolution of avian intelligence. Philos Trans R Soc Lond B Biol Sci 361:23-43.

Emery NJ, Clayton NS (2004): The mentality of crows: convergent evolution of intelligence in corvids and apes. Science 306:1903-1907.

-Feenders G, Liedvogel M, Rivas M, Zapka M, Horita H, Hara E, Wada K, Mouritsen H, Jarvis ED (2008): Molecular mapping of movement-associated areas in the avian brain: a motor theory for vocal learning origin. PLoS One 3:e1768.

-Finlay BK, Darlington RB (1995): Linked regularities in the development and evolution of mammalian brains. Science 268:1578-1584.

- Finlay BL, Darlington RB, Nicastro N (2001): Developmental structure in brain evolution. Behav Brain Sci 24:263-308.

Funke K (1989): Somatosensory areas in the telencephalon of the pigeon. I. Response characteristics. Exp Brain Res 76:603-619.

- Gentner TQ, Hulse SH, Bentley GE, Ball GF (2000): Individual vocal recognition and the effect of partial lesions to HVc on discrimination, learning, and categorization of conspecific song in adult songbirds. J Neurobiol 42:117-133.

-Glendenning K, Masterton R (1998): Comparative morphometry of mammalian central auditory systems: variation in nuclei and form of the ascending system. Brain Behav Evol 51:59-89.

-Güntürkün O, Melsbach G, Horster W, Daniel S (1993): Different sets of afferents are demonstrated by the fluorescent tracers fast blue and rhodamine. J Neurosci Methods 49:103111.

-Harvey PH, Clutton-Brock TH, Mace GM (1980): Brain size and ecology in small mammals and primates. Proc Natl Acad Sci USA 77:4387-4389.
Healy S, Guilford T (1990): Olfactory bulb size and nocturnality in birds. Evolution 44:339346.

Healy SD, Krebs JR (1992): Food storing and the hippocampus in corvids: amount and volume are correlated. Proc R Soc Lond B 248: 241-245.

Healy SD, Krebs JR (1996): Food storing and the hippocampus in Paridae. Brain Behav Evol 47:195-199.

Huber L, Gajdon GK (2006): Technical intelligence in animals: the kea model. Anim Cogn 9:295-305.

Hunt GR (1996): Manufacture and use of hook tools by New Caledonian crows. Nature 379: 249-251.

Iwaniuk AN, Heesy CP, Hall MI, Wylie DR (2008): Relative Wulst volume is correlated with orbit orientation and binocular visual field in birds. J Comp Physiol A Neuroethol Sens Neural Behav Physiol 194:267-282.

Iwaniuk AN, Hurd PL (2005): The evolution of cerebrotypes in birds. Brain Behav Evol 65: 215-230.

Iwaniuk AN, Wylie DRW (2006): The evolution of stereopsis and the Wulst in caprimulgiform birds: a comparative analysis. J Comp Physiol A Neuroethol Sens Neural Behav Physiol 192:1313-1326.

Jerison HJ (1973): Evolution of the brain and intelligence. New York, Academic Press.

Jerison HJ (1985): Animal intelligence as encephalization. Phil Trans R Soc Lond B Biol Sci 308:21-35.

Karten HJ, Hodos W (1967): A stereotaxic atlas of the brain of the pigeon. Baltimore, Johns Hopkins University Press.

Krebs JR, Sherry DF, Healy SD, Perry VH, Vaccarino AL (1989): Hippocampal specialization of food-storing birds. Proc Natl Acad Sci USA 86:1388-1392.

Kubke MF, Massoglia DP, Carr CE (2004): Bigger brains or bigger nuclei? Regulating the size of auditory structures in birds. Brain Behav Evol 63:169-180.

Kuenzel WJ, Masson M (1988): A Stereotaxic Atlas of the Brain of the Chick (Gallus domesticus). Baltimore, Johns Hopkins University Press.

Lefebvre L, Nicolakakis N, Boire D (2002): Tools and brains in birds. Behaviour 139:939-973.

-Lefebvre L, Whittle P, Lascaris E, Finkelstein A (1997): Feeding innovations and forebrain size in birds. Anim Behav 53:549-560.

- Martin GR, Wilson KJ, Martin Wild J, Parsons S, Fabiana Kubke M, Corfield J (2007): Kiwi forego vision in the guidance of their nocturnal activities. PLoS One 2:e198.

- Mezey S, Szekely AD, Bourne RC, Kabai P, Csillag A (1999): Changes in binding to muscarinic and nicotinic cholinergic receptors in the chick telencephalon, following passive avoidance learning. Neurosci Lett 270:75-78.

Nottebohm F (1981): A brain for all seasons: cyclical anatomical changes in song control nuclei of the canary brain. Science 214:13681370.
Nottebohm F, Nottebohm ME, Crane L (1986): Development and seasonal changes in canary song and their relation to changes in the anatomy of song-control nuclei. Behav Neural Biol 46:445-471.

Parent A (1986): Comparative Neurobiology of the Basal Ganglia. New York, Wiley.

- Pettigrew JD, Frost BJ (1985): A tactile fovea in the Scolopacidae? Brain Behav Evol 26:185195.

Plummer TK, Striedter GF (2002): Brain lesions that impair vocal imitation in adult budgerigars. J Neurobiol 53:413-428.

Portmann A (1946): Études sur la cérébralisation chez les oiseaux. I. Alauda 14:1-20.

-Prior H, Schwarz A, Gunturkun O (2008): Mirror-induced behavior in the magpie (Pica pica): evidence of self-recognition. PLoS Biol 6:e202.

Puelles L, Martinez de la Torre M, Paxinos G, Watson C, Martinez S (2007): The Chick Brain in Stereotaxic Coordinates: An Atlas Featuring Neuromeric Subdivisions and Mammalian Homologies. San Diego, Academic Press.

Raby CR, Alexis DM, Dickinson A, Clayton NS (2007): Planning for the future by western scrub-jays. Nature 445:919-921.

-Rehkämper G, Frahm HD, Zilles K (1991): Quantitative development of brain and brain structures in birds (Galliformes and Passeriformes) compared to that of mammals (Insectivores and Primates). Brain Behav Evol 37:125-143.

-Reiner A, Davis BM, Brecha NC, Karten H) (1984): The distribution of enkephalinlike immunoreactivity in the telencephalon of the adult and developing domestic chicken. J Comp Neurol 228:245-262.

- Reiner A, Karten HJ (1985): Comparison of olfactory bulb projections in pigeons and turtles. Brain Behav Evol 27:11-27.

Reiner A, Perkel DJ, Bruce LL, Butler AB, Csillag A, Kuenzel W, Medina L, Paxinos G, Shimizu T, Striedter G, Wild M, Ball GF, Durand S, Guturkun O, Lee DW, Mello CV, Powers A, White SA, Hough G, Kubikova L, Smulders TV, Wada K, Dugas-Ford J, Husband S, Yamamoto K, Yu J, Siang C, Jarvis ED (2004): Revised nomenclature for avian telencephalon and some related brainstem nuclei. J Comp Neurol 473:377-414.

Rieke GK, Wenzel BM (1978): Forebrain projections of the pigeon olfactory bulb. J Morphol 158:41-55.

Scharff C, Nottebohm F (1991): A comparative study of the behavioral deficits following lesions of various parts of the zebra finch song system: implications for vocal learning. J Neurosci 11:2896-2913.

Seed AM, Clayton NS, Emery NJ (2008): Cooperative problem solving in rooks (Corvus frugilegus). Proc Biol Sci 275:1421-1429.

Seed AM, Emery NJ, Clayton NS (2009): Intelligence in corvids and apes: a case of convergent evolution. Ethology 115:401-420. 
Sherry DF, Vaccarino AL, Buckenham K, Herz RS (1989): The hippocampal complex of food-storing birds. Brain Behav Evol 34:308317.

Shimizu T, Karten HJ (1993): The avian visual system and the evolution of the neocortex; in Zeigler HP, Bischof HJ (eds): Vision, Brain, and Behavior in Birds. Cambridge, MIT Press.

Smith GT, Brenowitz EA, Beecher MD, Wingfield JC (1997): Seasonal changes in testosterone, neural attributes of song control nuclei, and song structure in wild songbirds. J Neurosci 17:6001-6010.

-Sol D, Lefebvre L, Rodriguez-Teijeiro JD (2005): Brain size, innovative propensity and migratory behaviour in temperate Palaearctic birds. Proc Biol Sci 272:1433-1441.

- Stewart MG, Kabai P, Harrison E, Steele RJ, Kossut M, Gierdalski M, Csillag A (1996): The involvement of dopamine in the striatum in passive avoidance training in the chick. Neuroscience 70:7-14.

-Stingelin W, Senn D (1969): Morphological studies on the brain of sauropsida. Ann NY Acad Sci 167:157-163.
Teuchert G, Reissmann T, Vockel A (1986): Olfaction in Peking ducks (Anas platyrhynchos): a comparative study of centrifugal and centripetal olfactory connections in young ducks and in embryos and ducklings (Aves). Zoomorphology 106:185-198.

Timmermans S, Lefebvre L, Boire D, Basu P (2000): Relative size of the hyperstriatum ventrale is the best predictor of feeding innovation rate in birds. Brain Behav Evol 56: 196-203.

Watanabe S (2001): Effects of lobus parolfactorius lesions on repeated acquisition of spatial discrimination in pigeons. Brain Behav Evol 58:333-342.

Weir AA, Chappell J, Kacelnik A (2002): Shaping of hooks in New Caledonian crows. Science 297:981.

Wenzel BM (1968): Olfactory prowess of the kiwi. Nature 220:1133-1134.

Wenzel BM (1971): Olfactory sensation in the kiwi and other birds. Ann NY Acad Sci 188 183-193.

Whiting BA, Barton RA (2003): The evolution of the cortico-cerebellar complex in primates: anatomical connections predict patterns of correlated evolution. J Hum Evol 44:3-10.

-Wild JM (1985): The avian somatosensory system. I. Primary spinal afferent input to the spinal cord and brainstem in the pigeon $(\mathrm{Co}-$ lumba livia). J Comp Neurol 240:377-395.
Wild JM (1987): The avian somatosensory system: connections of regions of body representation in the forebrain of the pigeon. Brain Res 412:205-223.

Wild JM (1997): The avian somatosensory system: the pathway from wing to Wulst in a passerine (Chloris chloris). Brain Res 759: 122-134.

Wild JM, Farabaugh SM (1996): Organization of afferent and efferent projections of the nucleus basalis prosencephali in a passerine, Taeniopygia guttata. J Comp Neurol 365:306328.

Wild JM, Kubke MF, Carr CE (2001): Tonotopic and somatotopic representation in the nucleus basalis of the barn owl, Tyto alba. Brain Behav Evol 57:39-62.

Wild JM, Kubke MF, Pena JL (2008): A pathway for predation in the brain of the barn owl (Tyto alba): projections of the gracile nucleus to the 'claw area' of the rostral wulst via the dorsal thalamus. J Comp Neurol 509:156166.

Witkovsky P, Zeigler HP, Silver R (1973): The nucleus basalis of the pigeon: a single-unit analysis. J Comp Neurol 147:119-128. 